\title{
Triatoma melanosoma, Novo Status para Triatoma infestans melanosoma Martinez, Olmedo \& Carcavallo, 1987 (Hemiptera: Reduviidae)
}

\author{
Herman Lent, José Jurberg*, Cleber Galvão*, Rodolfo Ubaldo Carcavallo*^
}

\begin{abstract}
Centro de Ciências Biológicas, Universidade Santa Úrsula, Rua Jomalista Orlando Dantas 59, 22231-010 Rio de Janeiro, RJ, Brasil *Laboratório Nacional e Internacional de Referência em Taxonomia de Triatomíneos, Departamento de Entomologia, Instituto Oswaldo Cruz, Av. Brasil 4365, 21045-900 Rio de Janeiro, RJ, Brasil

${ }^{\star}$ CIBIOM Instituto de Neurobiologia, CONICET, Buenos Aires, Argentina
\end{abstract}

Triatoma melanosoma, new status for Triatoma infestans melanosoma Martinez, Olmedo \& Carcavallo, 1987 (Hemiptera: Reduviidae) - Triatoma infestans melanosoma was described in 1987 by Martinez, Olmedo \& Carcavallo. In the present work the authors make a redescription, adding new characters, and based on biological and morphological aspects raise up to the level of species and being identified as Triatoma melanosoma. A detailed morphological study of the external male genitalia was made.

Key words: Triatominae - Triatoma infestans - Triatoma melanosoma

Em 1987 Martinez et al. descreveram uma nova subespécie, Triatoma infestans melanosoma, totalmente negra e de fácil manutençāo em laboratório. A colônia iniciou-se a partir de espécimes capturados em 1984, no extremo nordeste da Argentina, na província de Misiones. Muitas geraçōes deste inseto foram mantidas em diversos laboratórios: Servicio Nacional de Chagas (Santa Maria de Punilla, Córdoba, Argentina); Instituto de Zoonoses (Buenos Aires); Insetário Regional (Posadas, Misiones, Argentina) e CIBIOM - Instituto de Neurobiologia (CONICET, Buenos Aires), bem como no Brasil, no Laboratório Nacional e Internacional de Referência em Taxonomia de Triatomíneos, Instituto Oswaldo Cruz (Rio de Janeiro) e na Faculdade de Saúde Pública (São Paulo).

Em milhares de insetos observados, nāo surgiu um único espécime com o fenótipo "normal" de Triatoma infestans (Klug, 1834), demonstrando que este triatomíneo não pode ser considerado um simples mutante. Portanto, o que era denominado $T$. $i$. melanosoma descrito como subespécie em 1987 e agora redescrito com adição de outros caracteres passa ser identificado como T. melanosoma n. comb.

Com auxílio do CNPq e Convênio BIRD/FNS/ FIOCRUZ no 27/93, Projeto "Controle das doenças endèmicas no nordeste".

Recebido em 20 de outubro de 1993

Aceito em 27 de julho de 1994

\section{MATERIAIS E MÉTODOS}

Foram utilizados espécimes de $T$. infestans de diversas áreas nas comparaçōes com $T$. melanosoma. Foram obtidas, ainda, informações de insetários argentinos onde foram feitas hibridizações e cruzamentos, entre geraçōes, com T. infestans.

Para o estudo da genitália externa masculina o nono segmento abdominal ou pigóforo foi retirado e aquecido por alguns minutos em solução de potassa a $10 \%$. Algumas estruturas precisaram ser diafanizadas com hipoclorito de sódio por serem completamente negras. A disseç̧ão foi deita em fenol e os desenhos com auxilio de câmara clara.

\section{RESULTADOS}

Há nove anos $T$. melanosoma vem sendo mantida em condiçōes de laboratório; nenhum espécime apresentou o fenótipo típico de $T$. infestans. Além disso os espécimes melânicos mutantes de $T$. infestans encontrados diversas vezes na natureza ou em colônias, mantêm nas últimas coxas e fêmures, a coloraçào pálida típica de $T$. infestans. Em colônias de T. melanosoma os insetos são totalmente negros e é difícil crer numa "perda total" da informaçāo genética cromática se a colônia estivesse relacionada à $T$. infestanss.

Através do Prof. MA Lopez, do insetário do Instituto de Zoonoses, tomamos conhecimento de que a hibridizaçào entre fêmeas de $T$. melanosoma e machos de $T$. infestans é relativamente fácil, mas a combinação sexual contrária é difícil. Em ambos os casos alguns espécimes são negros, alguns tèm o fenótipo de $T$. infestans típico e ou- 
tros são melânicos, porém apresentam coxas e trocânteres claros, amarelo palha.

Cabe ressaltar que híbridos de $T$. infestans sāo freqūentes em espécies como $T$. platensis Neiva, 1913 e T. delpontei Romaña \& Abalos, 1947 e estes híbridos férteis freqūentemente são encontrados no campo, especialmente nos arredores de habitaçōes rurais. No laboratório, o padrão genético dos hibridos de $T$. infestans com $T$. platensis e T. delpontei é o mesmo dos espécimes de $T$. melanosoma.

Nós consideramos que o triatomíneo descrito por Martinez et al. (1987) como T.i. melanosoma, apresentou diversos parâmetros biológicos, que podem levá-lo a ser considerado como espécie e, portanto, separado de $T$. infestans. As diferenças encontradas na genitália externa entre estas duas espécies devem ser consideradas com valores relativos, já que existe variabilidade nas estruturas fálicas em $T$. infestans de acordo com a distribuição geográfica (Lent \& Wygodzinsky 1979, Lent \& Jurberg 1985).

\section{REDESCRIÇÃO}

Triatoma melanosoma Martinez, Olmedo \& Carcavallo n. comb.

Sin.: Triatoma infestans melanosoma Martinez, Olmedo \& Carcavallo, 1987 Comprimento - fêmeas $25 \mathrm{~mm}$ - machos $23 \mathrm{~mm}$

Corpo de colorido totalmente negro; apenas a membrana dos hemélitros é de cor cinzenta escura. Tegumento revestido de pequenas cerdas.

Cabeça com comprimento igual ao do pronoto; tegumento rugoso e granuloso dorsalmente. Regiāo ante-ocular bem mais longa do que a pós-

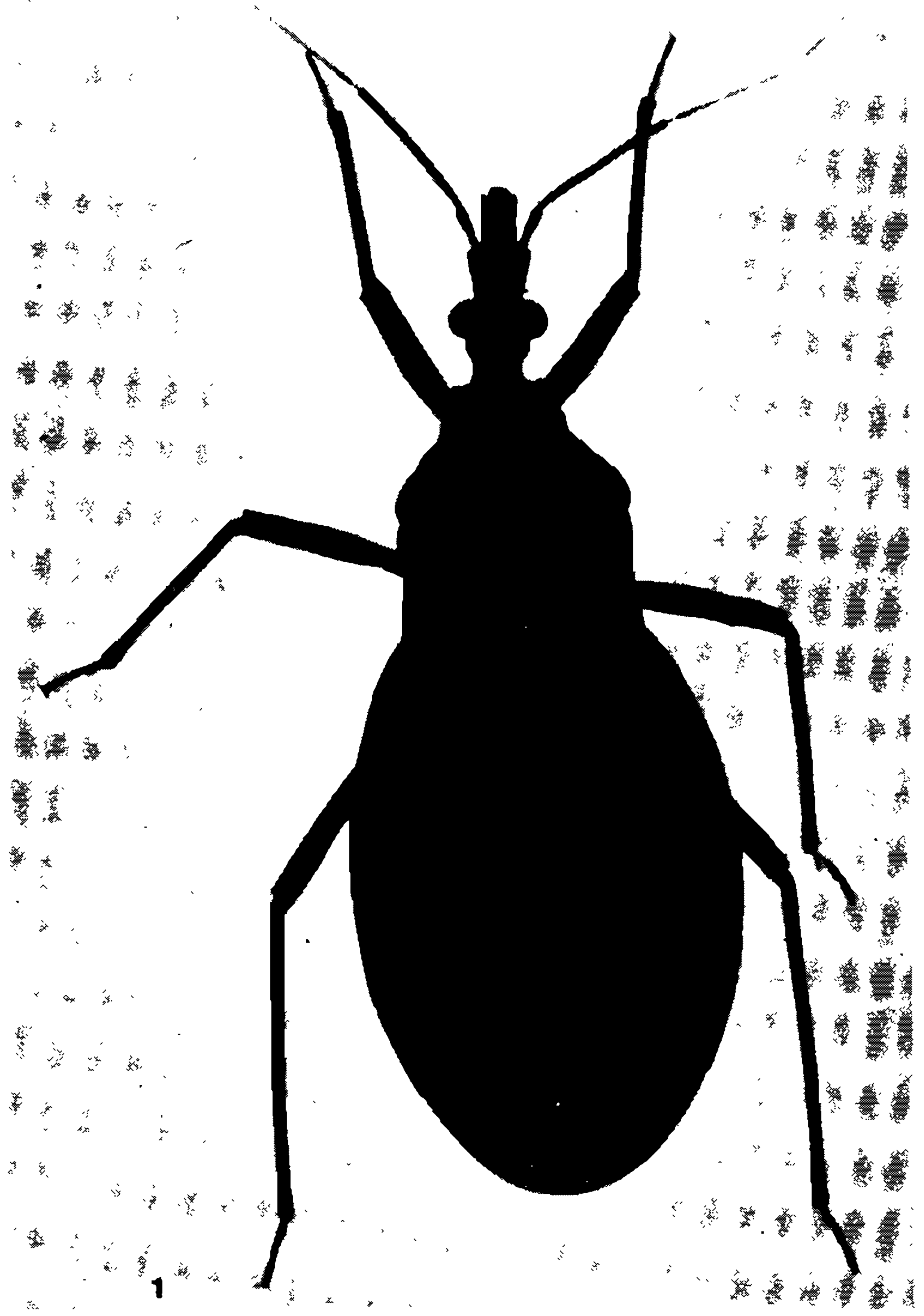

Fig. 1: Triatoma melanosoma Martinez, Olmedo \& Carcavallo, 1987, macho (original). 

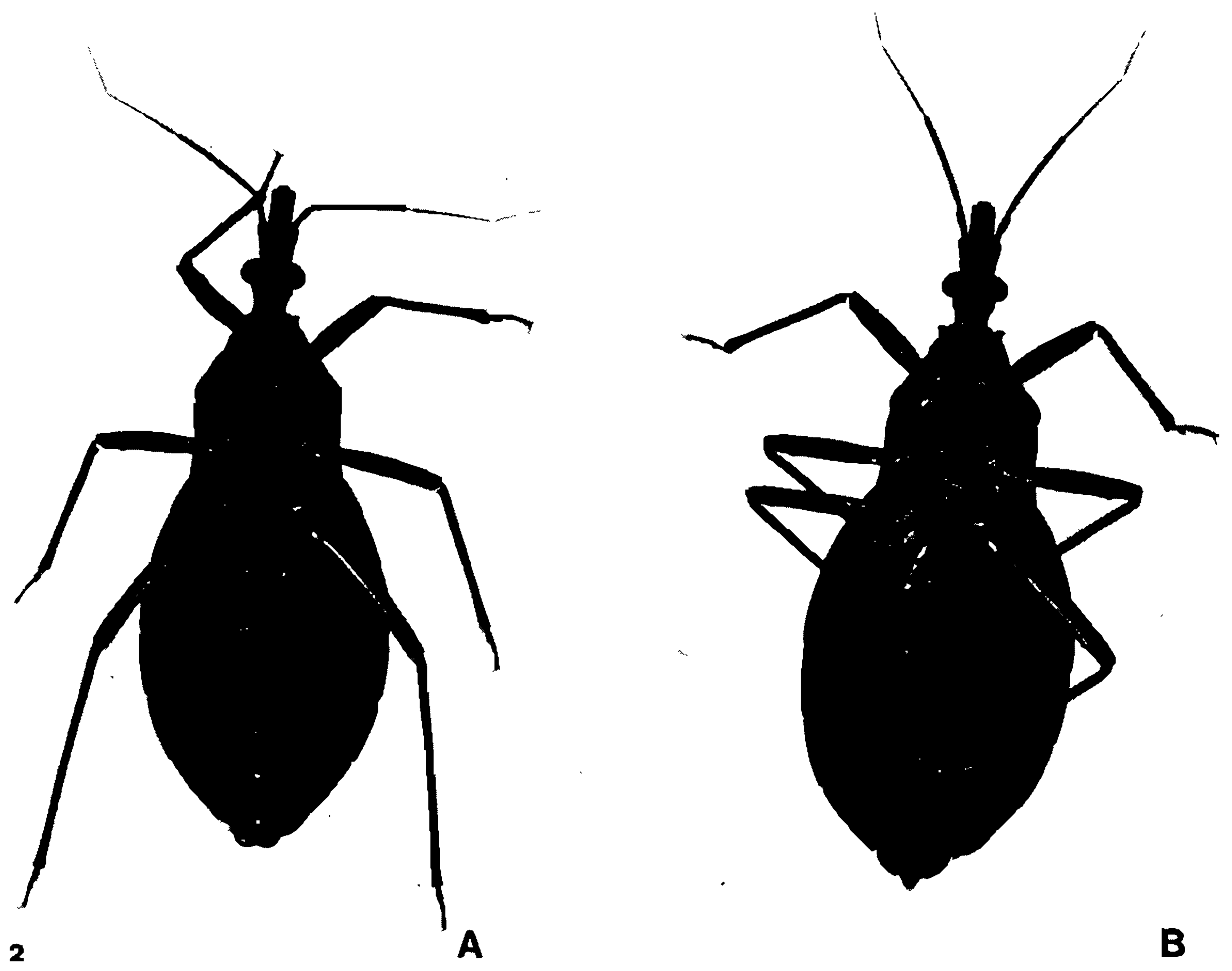

B

Fig. 2: Triatoma melanosoma Martinez, Olmedo \& Carcavallo, 1987, vista ventral a-macho b-fêmea (original).

ocular (4x); clípeo dilatado na base, as genas o ultrapassam levemente e as jugas são grandes e salientes. A distância inter-ocular dorsal é maior que a largura de um olho. Tubérculos anteniferos implantados no meio da região ante-ocular. De perfil, os olhos são distintamente mais globosos e atingem a face ventral da cabeça, mas não a dorsal. Os ocelos são grandes, bem projetados para os lados, afastados dos olhos e implantados ao nível do bordo posterior da cabeça.

Antenas com $01^{9}$ artículo quase atingindo o nivel do ápice da cabeça; $2^{\circ}$ artículo tão escuro quanto o $1^{2}$, revestido de pequenas cerdas; $3^{\circ}$ e $4^{9}$ artículos claros e com cerdas longas em número reduzido. Proporção: 1:3, 3:3, 0:2.

Rostro com o $1^{2}$ articulo largo, quase liso; $2^{9}$ articulo terminando ao nivel do bordo posterior dos olhos e com numerosas cerdas longas somente na sua face ventral; $3^{2}$ artículo mais fino $e$, aproximadamente, do comprimento do $1^{2} \mathrm{e}$ provido de denso tufo de cerdas longas e fortes. Relaçōes: 1:1, 8:1.

Pescoço liso.

Pronoto com lobo anterior com cerca de $1 / 3$ do posterior e dele pouco separado, com $1+1$ tubérculos medianos separados por sulco que se prolonga até $2 / 3$ do lobo posterior, dele partem $1+1$ cristas longitudinais até quase o término do lobo posterior e que se iniciam ainda no lobo anterior em $1+1$ saliências. $O$ lobo anterior é praticamente liso e o posterior é rugoso e granuloso. Os ângulos ântero-laterais são bem salientes, dirigidos para os lados e de ponta romba. Os ângulos humerais são arredondados.

Sulco estridulatório evidente aparentemente com sulcos pouco pronunciados. Esterno com poucas cerdas e pleuras com sulcos que sāo mais profundos nas metapleuras. 

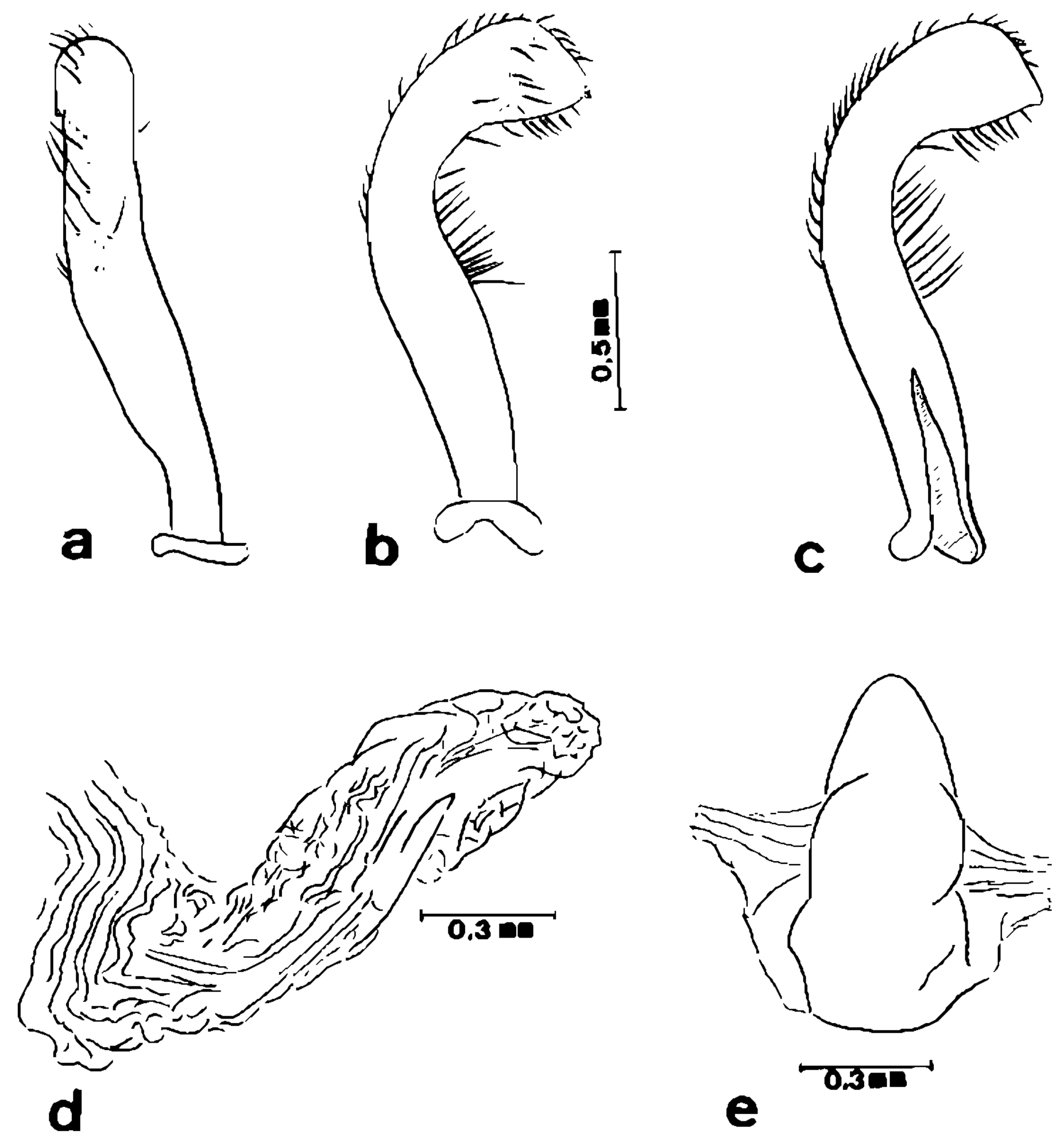

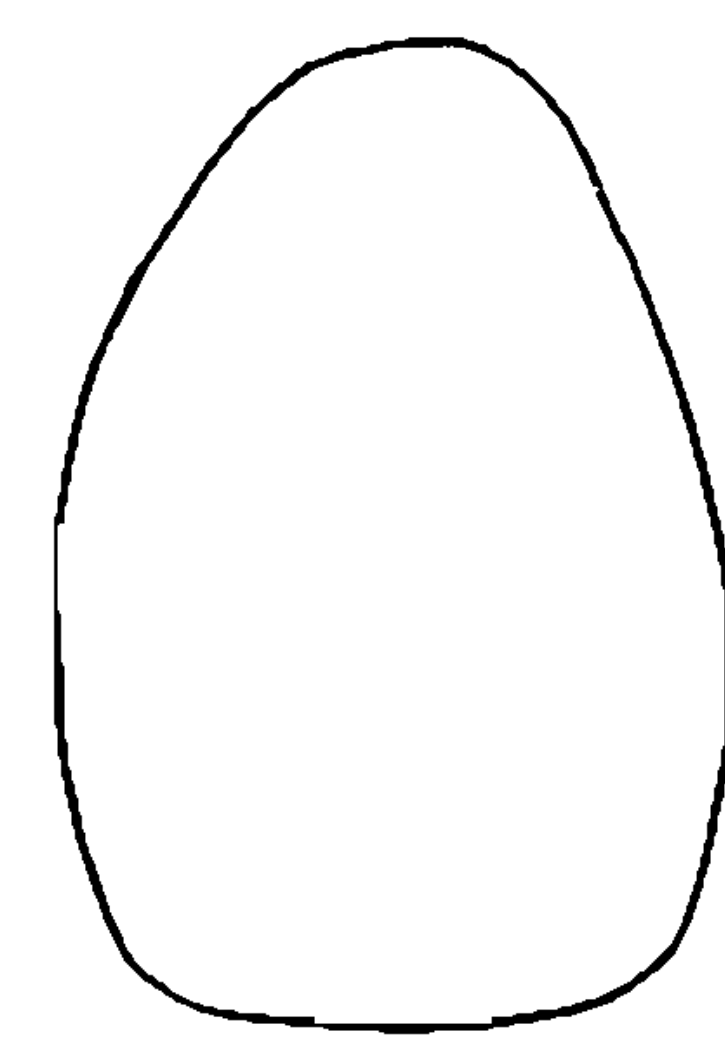

f

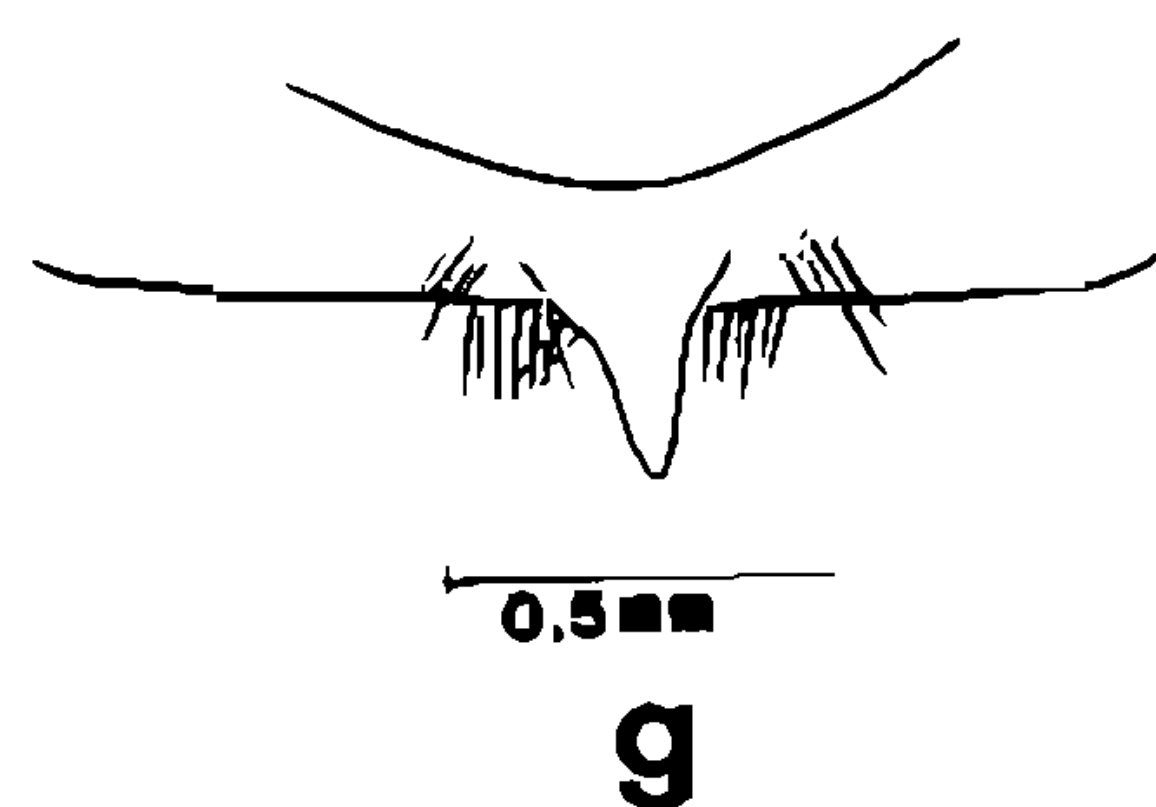

3

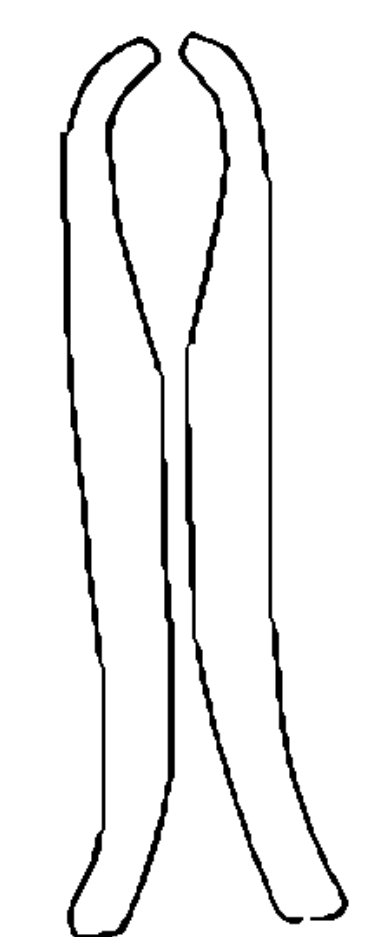

$\mathbf{h}$

Triatoma melanosoma Martinez, Olmedo \& Carcavallo, 1987 - genitália externa do macho - Fig. 3a,b,c parâmeras; d endosoma; e vesica; f falosoma; g processo mediano do pigóforo; h suporte do falosoma.

Escutelo parcialmente rugoso com $1+1$ tubérculos na base, afilado para o ápice cuja ponta é romba.

Hemélitros com cório, clavo e membrana sem maiores detalhes, essa não chegando a atingir a extremidade do corpo.

Patas relativamente delgadas e longas; fêmures um pouco dilatados e com pequenos espinhos no ápice; fossetas esponjosas presentes no $1^{8}$ e $2^{8}$ par de patas dos machos, ausentes nas fêmeas e substituidas por forte tufo de cerdas no ápice.

Abdome também negro na face ventral, porém com nítida linha venmelha cobrindo os sulcos inter-segmentares do conexivo principalmente quando observados pela face ventral. A pilosidade geral do abdome é reduzida e os estigmas respiratórios estão bem aproximados do conexivo em ambos os lados (Figs 1 e 2).

Genitália externa dos machos - O falo desta espécie é totalmente melânico a exemplo dos caracteres externos. Algumas estruturas, como por exemplo os parâmeros, tiveram que ser diafanizadas com hipoclorito de sódio para melhor serem observadas.

Parâmeros $(\mathrm{Pa})$ totalmente negros, robustos, arqueados no $1 / 3$ apical, com pequena projeção apical voltada para dentro; face externa sem cerdas; face interna com raros pêlos no ápice; bordos interno e externo com pêlos da regiāo média para o ápice (Fig. 3a,b,c). 


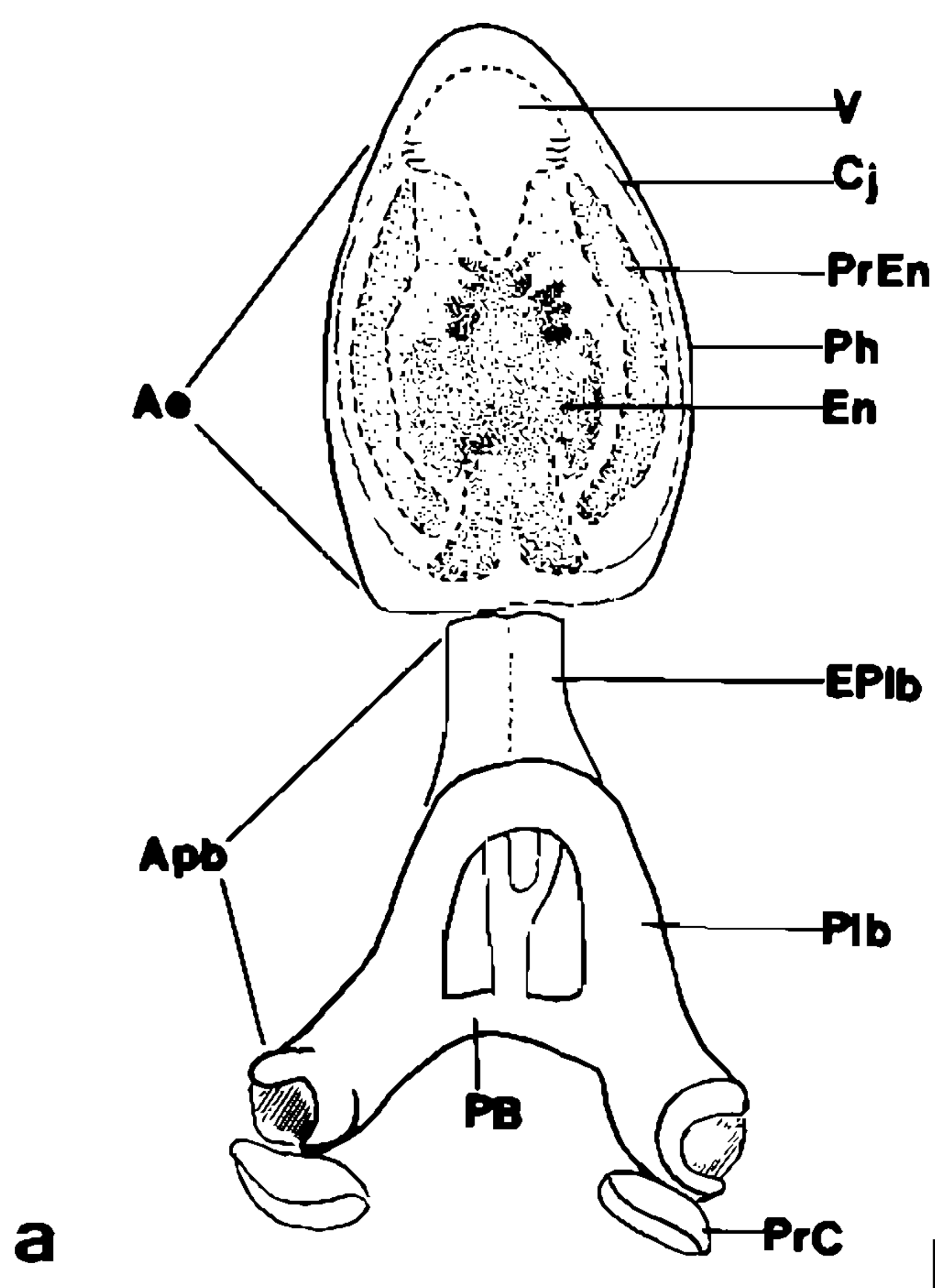

b
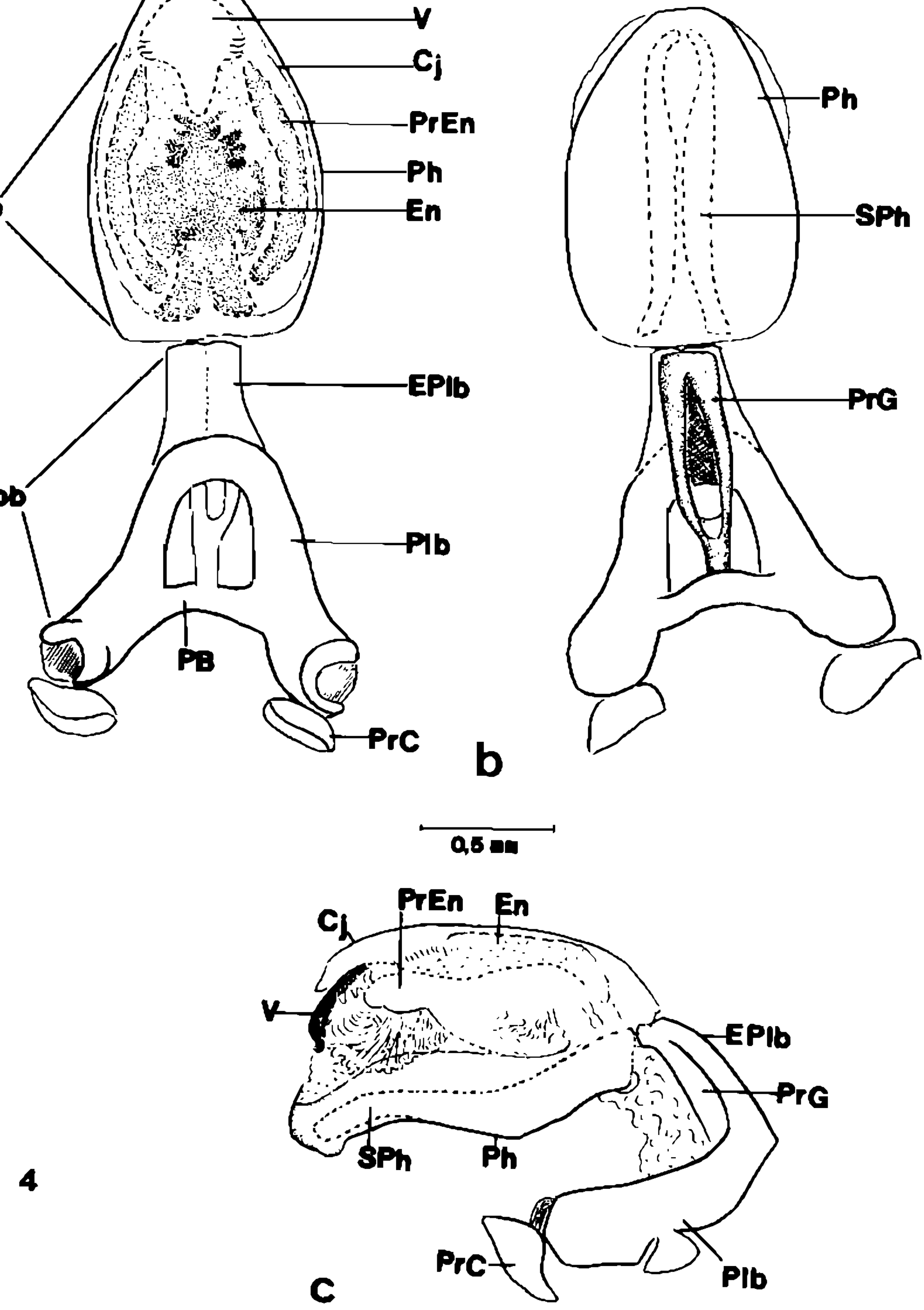

Triatoma melanosoma Martinez, Olmedo \& Carcavallo; 1987 - genitália extema do macho - Fig. 4: falo-a: vista dorsal; b: vista ventral; c: vista lateral. (Ac edeago; apb aparelho articular, Cj conjuntiva; En endosoma; Plb; E plb extensão mediana da placa basal; PB ponte basal; Ph falosoma; Plb placa basal; PrC processo capitati; PrEn processo do endosoma; Pro processo do gonoporo; $V$ vesica).

Processo mediano do pigóforo (PrP) triangular, curto, com ápice acuminado, totalmente negro com poucas cerdas na base (Fig. $3 \mathrm{~g}$ ).

Falosoma (Ph) ovóide, base retilínea, cobrindo lateralmente o edeago (Figs. 3f, 4b).

Suporte do falosoma (SPh) de tamanho médio, braços laterais livres no ápice onde os bordos internos são levemente abaulados (Figs. 3h e 4b).

Processo do endosoma (PrEn) aliforme, alongado sem estrias e sem espinhos no ápice (Figs. 3d, 4a,c).

Vésica (V), vista pela face dorsal, apresentase como uma placa laminar, bordos laterais delineando três áreas distintas: a apical acuminada, a mediana arredondada e a basal com o bordo inferior retilíneo (Figs. 3e, 4a, c).

Processo do gonoporo (PrG) com base cilindrica curta de onde se origina um tubo cilindrico, oco, fendido longitudinalmente (Fig. 4b, c).

Extensão mediana da placa basal (EP1b) constituída por uma placa laminar curta, com indicação de separaçāo mediana; seu comprimento é de 1/3 do aparelho articular (Apb), 2/3 pertencem à placa basal (P1b) (T. infestans 1:1) (Fig. 4a, c).

Localidade-tipo: Misiones, Depto San Ignácio, Colonia Santa Rosa, Argentina

Holótipo macho 
Alótipo fêmea

Coleção: Museo Argentino de Ciências Naturales, Museo de La Plata, na Argentina; Instituto Oswaldo Cruz, no Brasil; American Museum of Natural History, USA.

\section{REFERENCIAS}

Lent H. Jurberg J 1985. Sobre a variação intra especifica em Triatoma dimidiata (Latreille) e Tri- atoma infestans (Klug) (Hemiptera, Reduviidae). Mem Inst Oswaldo Cruz 80: 285-299.

Lent H, Wygodzinsky P 1979. Revision of the Triatominae (Hemiptera, Reduviidae) and their sig. nificance as vectors of Chagas'disease, Bull Amer Mus Nat Hist 163: 123-520

Martinez A, Olmedo RA, Carcavallo RU 1987. Una nueva subespecie argentina de Triatoma infestans. Chagas 4: 479-480. 